\title{
Analysis on Satisfaction using Interference as Mediator"
}

\author{
Sheeja Krishnakumar ${ }^{1 *}$ and Juin Choudhury ${ }^{2}$ \\ ${ }^{1}$ Assistant Professor, Kristu Jayanti College, Kothanur - 560077, Bangalore, Karnataka, India \\ ${ }^{2}$ Associate Professor, Acharya School of Management, Soldevanahalli - 560090, \\ Hesaraghatta Main Road, Bangalore, Karnataka, India
}

\begin{abstract}
Job satisfaction explains the comfort and the content with the job of an individual. The enjoyment that an individual receive while performing the job makes the result of the job a favorable one and result in high level of satisfaction. Family satisfaction is the amount of happiness shared by the family members to fulfill their needs and interests. This study gives emphasis on both job and family satisfaction. This study tries to find out whether interference of work to family has any influence to family satisfaction and family-work interference has any influence on the job satisfaction. Understanding these aspects and bringing changes based on that can transform the work place to a fruitful place for growth and sustainability. More women are entering to information technology companies and contributing much to the success of the organization. Study is focused to women in information technology to find out the interference and satisfaction. Four selected information technology companies based in Bangalore are considered for the study. Questionnaires are prepared and emailed to the women employees. Three hundred and seventy one samples are collected. Full time women employees with minimum of one year experience in that particular company are considered in the study. In this study Hayes Regression test is done to find out the effect of mediating variable between dependent and independent variables. From the study it is found that mediating variables like work-family interference and family-work interference is not mediating between job satisfaction and family satisfaction and vice-versa.
\end{abstract}

Keywords: Employees, Family, Job, Satisfaction, Women

\section{Introduction}

The entrance of women folk into the organization has caused imbalance in the family structure. This results in weakening of the quality of family and social life. Economic independence of women in some cases has resulted in divorces, single-parent families and breakage of joint families to nuclear one. Another problem faced by the women employees include extension of work hours, more demand for the job leads to stress and exhaustion. This extra exertion is affecting health and unnecessary family disputes which can be defined as an imbalance of work and life. For most of the women it is the bringing together of the responsibilities of taking care of the family and that of work. For others, it is the overlapping of the pressure from family domain to work and vice versa. Studies have shown that involvement of men in employment is high while compared to women. This states that women are engaged more in the other activities like care of children, elderly members and other household chores. Recent trend has shown that contribution of females in the work force has stimulated the economy. This has forced the organization to understand and

"Email: sheeja.k@kristujayanti.com

"This is the revised and modified version of the article, originally presented in the $7^{\text {th }}$ International Conference on Managing Human Resources at the workplace, December 14-15, 2018, SDMIMD, Mysuru, India. 
gather the requirements of women to attract and retain them within.

Urbanization has changed many of the family structure. Many of the joint families have opted for nuclear one. Support from other members of the family reduced. So, balancing job and family has become an issue to take jobs in the organization. Due to the rise in cost of living it has been imperative for the woman to support the family, especially educated woman. The realization that dual earning can make a better living has forced woman to get employed. The role woman played in the organization has been appreciated and encouraged. The imbalance of work and family life has been noticed and a need to support them was felt. When the demands from both end increases the imbalance is sensed. This research paper tries to find out whether there is interference on satisfaction among women employees working in information technology companies in Bangalore. In order to find out the impact on job satisfaction, the family satisfaction aspect has to be studied to understand the interference.

\section{Women and New Age Technology}

This is the age of technology. In the year 1958, the word information technology was introduced and was used in the context where effort of human beings can be reduced. It is applicable to simple technology to a complicated one. The positive part of it is that it reduces the effort of human on the job. Information technology has offered solution through numerous algorithms. These companies require intelligence and less of manual work. This attracts more females to these job opportunities. There are companies who use information technology to generate revenue but there are other companies with the help of this technology produce high quality products to increase profits. In general it is found that information technology plays a major role to satisfy the needs of the clients. In India, most of the companies are service providers and clients are the strength of the company. There is lot of demands for the professionally qualified technicians who are technically sound and focused. The job demands lot of technical skill. This opportunity is utilized by many women to enter this sector with relevant qualification.
It is estimated that this market is growing at the rate of $21 \%$. There is lot of demand of information technology in the areas like telecom, healthcare, financial services, educational sector, cloud computing, government related sector and other industries. This reveals the increasing growth rate of information technology in future. The future of information technology sector is bright. India is developing in the areas like artificial intelligence, gaming and other related areas. Till now the development is to provide services to the customers but it has to go beyond that.

The growth of this sector is bright and opportunities are many. Unlike manufacturing sector, the nature of job and the ease of working are favorable for women employees. Companies also initiated many programs for employees to maintain equilibrium between work and family life, especially for women.

\section{Facilities Provided by Information Technology Companies}

Companies are providing facilities after understanding the difficulties of the employees to cope up with the heavy workload and family commitment. Most of the information technology companies are providing some initiatives to have a healthy balance between the responsibilities to the job and that of the family. Some of the programs initiated are child care centers adjacent to the organization, in-home care facilities for the related family members in case of emergency, health care facilities, teaching assistance for employees' kids, advisory services related to financial and legal issues, relocation support for the employees without compromising the remuneration and other benefits that they are enjoying at present. Some companies conduct workshops related to parenting, child attitude, elder care, life-skill and health care improve bonding among the family members. Apart from these companies conduct free meditation, yoga classes, medical check-ups, and gymnasium facility and physiotherapy sessions. These programs take care of their overall development of their health and improve the lifestyle of the employees to contribute an excellent performance in the company. There are companies providing subsidized food and beverages, healthy food in the canteen and medical insurance that cover the whole family. 
While providing these facilities to employees, they do not have to go in search of these requirements outside and waste their precious time. These are provided in the office premises and utilization of these improves job performance. Some of the initiatives improve the bonding with family members. Apart from the rewards and recognitions for the individual contributions, there are appreciations for the team activity. Companies try to see that employees are commitment and satisfaction towards their job. For the satisfaction towards their family, companies provide facilities like crèche, educational support to kids, flexible working etc. There are recognitions for special leadership skill, innovative ideas and creative decision making. These encourage employees to be committed and enjoy working in the company and reduce the feeling of imbalance of work and family life. Identifying career growth path for high performers is also another initiative related to it.

Even though there are many facilities and support provided by the company, this study tries to find that any interference from family life is affecting the work life and vice versa. Any dissatisfaction in family life would have an impact on work life. So this study tries to find out satisfaction from family to work life and back, from work life to family life.

\section{Work - Family Interference - Literature Review}

The literatures are examined to find out whether interference of family domain to work domain or vice versa lead to conflict and cause disruption in the satisfaction.

The paper of Frone, Yardley, Markel (1997) tried to build up and analyze an integrative model of the interface of work and family that explains better compared to the previous study. The results of the study disclosed that conflict from family to job had an indirect effect on the conflict from work to family. The conflict from family to work negatively affected work performance. Also conflict from job to family had been negatively related to family life. This revealed the interference of life from one domain into another result in less performance in the other life.
Frone et al., (1992) developed and analyzed a comprehensive model of the interface of work and family. This model was an extension of the research conducted prior to this. The influence of gender, race and job type was also tested. Study revealed that there was a relationship between conflict of work to family and family - work conflict and the relation was positive and reciprocal. This was proved in previous studies (Beutell \& Greenhaus, 1985). It was found that job stressors and job involvement were related positively to work-family conflict. Alternatively, family stressors and family involvement were related positively to family-work conflict. As hypothesized in the study work family conflict was related positively to family distress. Family-work conflict was related positively to work distress. This proved that there was interference from one role to another based on the demands and responsibilities in the particular role. The main hypothesis was opposite to the past research that workfamily conflict was related negatively to both job and family satisfaction.

Ford et al., (2007) the Meta analysis was to test quantitatively the model that has empirical support by individual studies of Carlson and Kacmar (2000) and Frone et al., (1992a). The study explained about cross domain relations that explained about variables in the work domain to the family satisfaction and the variables in the family domain to work satisfaction. In the model proposed by Ford, considered work family conflict. But Frone et al., (1992a) explained about work family interference as a mediating factor and work domain factors negatively influence family satisfaction. The results stated that there were relationship between variables related to job and family satisfaction. Work hours were related positively to family satisfaction. But interference of work to family was not a complete mediator but is related positively to family satisfaction.

This study by Carlson, Kacmar and Williams (2000) considered six dimensions. In that three were related to work - family conflict such as time, strain and behavior. Other two were interference from each domain. The study measured the content adequacy, reliability, construct validity, factor structure invariance and dimensionality of the scale. This scale was created so 
that it was easy for researchers to measure these six dimensions.

The relation of conflict from work to family, wellbeing, job-family satisfaction and support from family and colleagues were studied among the working employees (O'Driscoll, Brough, Kalliath, 2004). Colleagues support was found to moderate work-family interference and family satisfaction. But support from family did not act as a moderator. According to this study, both interferences didn't impact job satisfaction or well- being.

In the study ofLuk and Shaffer (2005) tried to understand the cross domain influences of stressors from work and family and interferences from both sides. Work domain antecedents considered were time commitment and work role expectation while the antecedents of family domain were parental demands. Work and family support were found to have moderating effects.

Duxbury, Higgins and Mills (1990) in their study try to find the intrusion from work into family and from family to work. The significance of interference of work to family, family to work and overload in relation with gender, after-hour telecommunicating and total hours had been tested in this study. From the study it is clear that there is a relation that is significant between the independent variables total hours and after-hour telecommunicating but no significant relation between dependent variables and gender. Study made it clear that women found after-hour telecommunication as overload while compared to men. Another prominent finding was that interference from work to family was greater than from family to work.

Ford, Heinen and Langkamer (2007) in their study a model of work-family interface had been created and tested. A sample was taken from a service oriented financial company who are parents or married were considered for the study. The model proposed was tested using structural equation modeling and found to be supportive. This study was an extension of the model suggested by Frone et al., (1992a). In this study difference between the interference of work with family (work to family conflict) and that of family with work (family to work conflict) was looked upon. Here the conflicting measures were considered as the key mediating variables linking work and family domain variables.

The study by Huang, Hammer, Neal and Perrin (2004) did a study on the relationship between conflict of work-family and vice-versa using longitudinal research design on dual-earner couples caring for both children and aging parents. The mediating effects of role related satisfaction between work-to-family conflict and family-to-work conflict was tested and found that there was no significant mediating effect of rolerelated satisfaction between them. Study found the direct relationship between family to work and work to family conflict through job satisfaction. This showed that job satisfaction did not mediate the relationship. This was contradictory to the existing study of (Frone et al., 1997).

\section{Objectives}

- To find the mediating effect of work-family interference between job satisfaction and family satisfaction and family-work interference between family satisfaction and job satisfaction.

\section{Hypothesis}

H1: There is a significant mediation of work-family interference between job satisfaction and family satisfaction.

$\mathrm{H} 2$ : Significant mediation of family-work interference between family satisfaction and job satisfaction

\section{Methodology}

The study was conducted by collecting data from women employees working in selected information technology companies. Around two hundred questionnaires were distributed but only one hundred and fifty one filled samples were received. The remaining filled questionnaires were received from emails. Total of three hundred and seventy one questionnaires were collected to do the analysis. Questionnaire contains demographic variable and variable related to the study. There were five 
items each from each family satisfaction, job satisfaction, work-family interference and family-work interference. Demographic variables include age, marital status, status of having kids, amount of time at work place. Likert's scale is used for the questionnaire. Mediation test is conducted to find out the influence of mediator variable on the independent variable for the cause of the dependent variable. For doing mediation analysis Hayes Regression was conducted. Initially job satisfaction was considered as causal variable and family satisfaction as outcome variable. Work-family interference was the mediating variable. In the second test family satisfaction was causal variable and job satisfaction is outcome variable. Family-work interference was considered as mediating variable in the second case.

\section{Analysis}

All the respondents were women employees and were full time employees. Out of 371 respondents, 58.2\% were between the ages of $20-30,35.3 \%$ were between the ages of $31-40$, and $6.2 \%$ between $41-50$ and the rest $0.3 \%$ of respondents were above the age of 50 . In the marital status $62.3 \%$ respondents were married and rest of the respondents were stated as single. $46.1 \%$ were stated that they had children and rest of the respondents stated that they had no children. $59.8 \%$ of respondents spent 9 hours in the office. $25.1 \%$ about 8hours, there were $14 \%$ respondents work for 10 hours, $0.3 \%$ for $11 \mathrm{hrs}, 0.5 \%$ for $12 \%$, there are even employees working for $13 \mathrm{hrs}$, of $0.3 \%$.

Mediation is the influence of mediator variable on the independent variable for the cause of the dependent variable. In other words, instead of the effect of $X$ (independent) on Y (dependent) directly, it is caused through $\mathrm{M}$, the mediator. The relationship between the independent and the dependent is not direct and is said to be indirect. The relationship can be represented in the form of a path model.

A mediation analysis was performed using the Hayes approach (2005) causal steps approach. The initial causal variable was Job Satisfaction, the outcome variable was Family Satisfaction and the proposed mediating variable was Work-Family Interference.

\subsection{Hypothesis 1}

8.1 .1

H1: There is a Significant Mediation of Work-Family Interference Between Job Satisfaction and Family Satisfaction

Job Satisfaction and Family Satisfaction with WorkFamily Interference as Mediators

$\mathrm{Y}=$ FS, Family Satisfaction as DV

$\mathrm{X}=\mathrm{JS}$, Job Satisfaction, as IV

$\mathrm{M}=\mathrm{WFI}$, Work to Family Interference as mediator

Total effect $(C)=a b+c^{\prime}$

$\mathrm{a}=$ Effect of $\mathrm{X}$ (independent variable) on $\mathrm{M}$ (mediator)

$\mathrm{b}=$ Effect of $\mathrm{M}$ (mediator) on Y (dependent variable) When Both X (independent variable) and M (mediator) are Present

$c^{\prime}=$ Direct Effect of X (independent variable) on Y ( $\left.c^{\prime}\right)$ When M (Mediator) is also Present

$\mathrm{c}=$ Total effect $\mathrm{X}$ (independent variable) on $\mathrm{Y}$ (dependent variable)

There are 4 steps involved. The first is the relationship between job satisfaction (independent variable) and work-family interference (mediator). The second step is the relationship between work-family family interference (mediator) and family satisfaction (dependent variable) in the presence of independent variable. The third step is the relationship between job satisfaction (independent variable) and family satisfaction (dependent variable) in the presence of the work family interference (mediator). This relationship should be insignificant if the presence of mediator is functioning. (Here here it is not functioning as it is significant). Finally the direct relationship between job satisfaction (independent variable) and family satisfaction (dependent variable) is tested. The second 


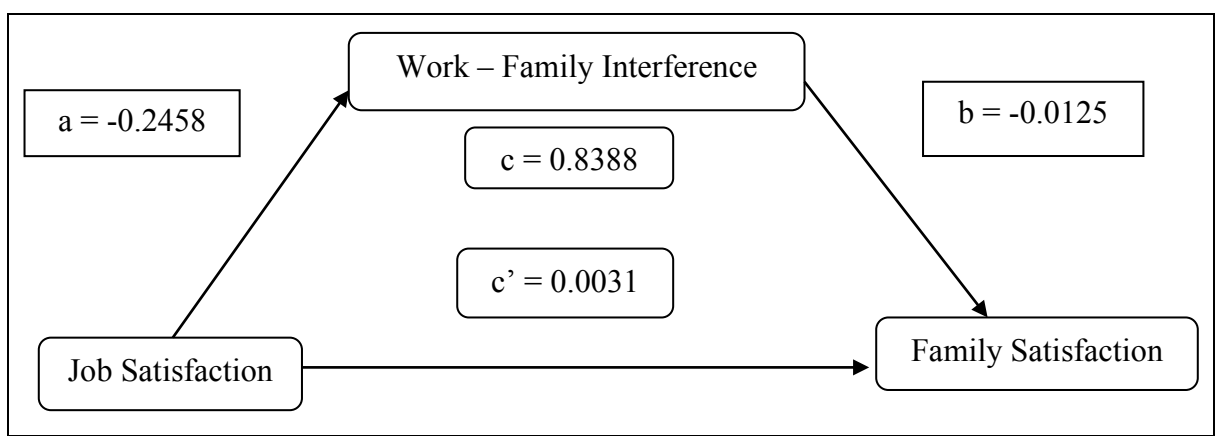

Figure 1. Mediating Effect of WFI between JS and FS.

Table 1. Hayes Regression Results

\begin{tabular}{|l|l|l|l|l|l|l|}
\hline Steps & Output & Input & Co-eff. & $\mathbf{T}$ & $\mathbf{P}$ & Interpretation \\
\hline 1 & WFI & JS & -0.2458 & -4.578 & 0.00 & IV significant predictor of M \\
\hline 2 & FS & WFI & -0.0125 & -0.687 & 0.49 & M not predictor of DV in the presence of IV \\
\hline 3 & FS & JS & 0.8357 & 43.2017 & 0.00 & IV significant predictor of DV in the presence of M \\
\hline 4 & FS & JS & 0.8388 & 44.6073 & 0.00 & IV significant predictor of DV \\
\hline
\end{tabular}

Table 2. Mediating effect of WFI between JS and FS

\begin{tabular}{|c|c|c|c|c|c|c|}
\hline \multicolumn{7}{|c|}{ Total effect of $X$ on $Y$} \\
\hline Total & Effect & Std $E$ & $T$ & $P$ & $\mathrm{LLCl}$ & ULCl \\
\hline & 0.8388 & 0.0188 & 44.607 & 0.00 & 0.8018 & 0.8758 \\
\hline \multicolumn{7}{|c|}{ Direct effect of $X$ on $Y$} \\
\hline \multirow[t]{2}{*}{ Direct } & Effect & Std $E$ & $\mathrm{~T}$ & $P$ & LLCl & ULCI \\
\hline & 0.8357 & 0.0193 & 43.202 & 0.00 & 0.7977 & 0.8737 \\
\hline \multicolumn{7}{|c|}{ Indirect effect of $X$ on $Y$} \\
\hline Indirect & Effect & Boot & Std E & BootLLCl & BootULCl & \\
\hline WFI & 0.0031 & 0.0049 & -0.006 & 0.01 & & \\
\hline
\end{tabular}

and third steps are done in the same regression model (Figure 1).

The regression of job satisfaction on the mediator, workfamily interference was significant, $\mathrm{b}=-0.2458, \mathrm{t}=$ $-4.578, p=<0.001$. The mediation process showed that the relationship between the work-family interference (mediator) and family satisfaction in the presence of job satisfaction was not significant, $\mathrm{b}=-0.0125, \mathrm{t}=-0.687$, $\mathrm{p}=0.49$. The result extracted from the data showed that the direct effect of job satisfaction on family satisfaction with the presence of work-family interference as a mediating factor was significant at $t=43.2017$, Lower Level Confidence Level (LLCI) is -0.006 and Upper Level Confidence Level (ULCI) is 0.01 . The $b=0.0031$, not significantly greater than zero. In the next step of analysis revealed that there was a significant relationship between job satisfaction (independent) variable and family satisfaction $t=44.6073$. This showed that there was no reduction in the effect of the relationship between independent and dependent variable in the presence of the mediator so there was no mediating effect here. So null hypothesis is accepted and alternate hypothesis is rejected (Table 1\&2).

\subsection{Hypothesis 2}

\section{2 .1}

H2: Significant Mediation of Family-Work Interference Between Family Satisfaction and Job Satisfaction 
$\mathrm{Y}=\mathrm{JS}$, Job Satisfaction as Dependent Variable

$\mathrm{X}=\mathrm{FS}$, Family Satisfaction, as Independent Variable

$\mathrm{M}=\mathrm{FWI}$, Family to Work Interference as mediator

Total effect $(\mathrm{C})=\mathrm{ab}+\mathrm{c}$

$\mathrm{a}=$ Effect of $\mathrm{X}$ (independent variable) on M (Mediator)

$\mathrm{b}=$ Effect of $\mathrm{M}$ (Mediator) on Y (dependent variable)

When Both X (independent variable) and $\mathrm{M}$ are Present

$c^{\prime}=$ Direct Effect of X (independent variable) on Y (c') When M (Mediator) is also Present

$\mathrm{c}=$ Total effect $\mathrm{X}$ (independent variable) on $\mathrm{Y}$ (dependent variable)
As explained before there are 4 steps involved. The first is the relationship between family satisfaction (independent variable) and family-work interference (mediator). The second step is the relationship between family-work interference (mediator) and job satisfaction (dependent variable) in the presence of independent variable. The third step is the relationship between family satisfaction (independent variable) and job satisfaction (dependent variable) in the presence of the family-work interference (mediator). This relationship should be insignificant if the presence of mediator is functioning. Finally the direct relationship between family satisfaction (independent variable) and job satisfaction (dependent variable) is tested. The second and third steps are done in the same regression model (Figure 2).

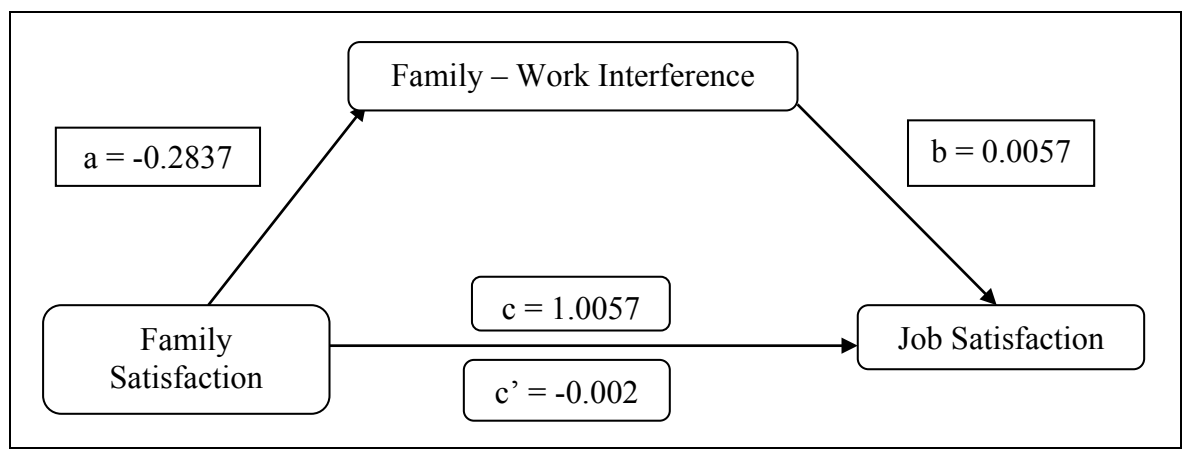

Figure 2. Mediating effect of FSI between FS and JS.

Table 3. Hayes regression results for $2^{\text {nd }}$ test

\begin{tabular}{|l|l|l|l|l|l|l|}
\hline Steps & Output & Input & Coeff. & $\mathbf{T}$ & $\mathbf{p}$ & Interpretation \\
\hline 1 & FWI & FS & -0.2837 & -4.9477 & 0.00 & IV significant predictor of M \\
\hline 2 & JS & FWI & 0.0057 & 0.2765 & 0.78 & M not predictor of DV in the presence of IV \\
\hline 3 & JS & FS & 1.0073 & 43.2123 & 0.00 & IV significant predictor of Y in the presence of M \\
\hline 4 & JS & FS & 1.0057 & 44.6073 & 0.00 & IV significant predictor of DV \\
\hline
\end{tabular}

Table 4. Mediating effect of FWI between FS and JS

\begin{tabular}{|c|c|c|c|c|c|c|}
\hline \multicolumn{7}{|c|}{ Total effect of $X$ on $Y$} \\
\hline \multirow[t]{2}{*}{ Total } & Effect & SE & $T$ & $P$ & $\mathrm{LLCl}$ & ULCl \\
\hline & 1.0057 & 0.0225 & 44.607 & 0.00 & 0.9614 & 1.05 \\
\hline \multicolumn{7}{|c|}{ Direct effect of $X$ on $Y$} \\
\hline \multirow[t]{2}{*}{ Direct } & Effect & SE & $T$ & $\mathrm{P}$ & $\mathrm{LLCl}$ & ULCl \\
\hline & 1.0073 & 0.0233 & 43.212 & 0.00 & 0.9615 & 1.0531 \\
\hline \multicolumn{7}{|c|}{ Indirect effect of $X$ on $Y$} \\
\hline Indirect & Effect & Boot & SE & BootLLCI & BootULCI & \\
\hline FWI & -0.002 & 0.0065 & -0.014 & 0.01 & & \\
\hline
\end{tabular}


The regression of job satisfaction on the mediator, work-family interference was significant, $b=-0.2837$, $\mathrm{t}=-4.9477, \mathrm{p}=0.00$. The mediation process showed that the relationship between the mediator, work-family interference, and family satisfaction in the presence of job satisfaction was not significant, $\mathrm{b}=0.0057, \mathrm{t}$ $=0.2765, \mathrm{p}=0.78$. The result extracted from the data showed that the direct effect of job satisfaction on family satisfaction with the presence of work-family interference as a mediating factor was significant at $\mathrm{t}=43.2123$ Lower Level Confidence Level (LLCI) is -0.00143 and Upper Level Confidence Level (ULCI) is 0.01 . The $b=-0.002$, not significantly greater than zero. In the next step of analysis revealed that there was a significant relationship between family satisfaction (independent) variable and job satisfaction $\mathrm{t}=44.6073$. This showed that there was no reduction in the effect of the relationship between family satisfaction and job satisfaction in the presence of the mediator, familywork interference, so there was no mediating effect here. So null hypothesis is accepted and alternate hypothesis is rejected (Table $3 \& 4$ ).

\section{Discussion}

A mediation analysis was performed using the Hayes approach (2005). It is causal steps approach. The initial causal variable considered has been job satisfaction and the outcome variable was family satisfaction and the proposed mediating variable was work to family interference. Same way mediating effect of family to work interference between family satisfaction and job satisfaction is also studied. The analysis revealed that there was a significant relationship between job satisfaction (independent) variable and family satisfaction in the presence of mediator. This showed that there was no reduction in the effect of the relationship between independent and dependent variable in the presence of the mediator so there was no mediating effect here. In the second mediation analysis, the initial causal variable was Family Satisfaction, the outcome variable was Job
Satisfaction and the proposed mediating variable was family-work interference. The analysis revealed that there was a significant relationship between family satisfaction (independent) variable and job satisfaction in the presence of mediator. This showed that there was no reduction in the effect of the relationship between family satisfaction and job satisfaction in the presence of the mediator, family-work interference, so there was no mediating effect here (Table 5).

\section{Conclusion}

The study was related to the mediating effect of mediating variable on the independent variable to have an impact on the dependent variable. In this study it was found that there is no significant influence of the mediator in the relation. The interference of work to family and family to work is not mediating in between job and family satisfaction and also between family and job satisfaction. Influence of family satisfaction is not affected by the interference of the work related issues and in the same way job satisfaction is influenced by family related interference. There is no change in the relation between job satisfaction and family relation because of the mediator. This explains that the interference has no impact on family satisfaction towards job satisfaction. Family satisfaction is important and contributes to the job satisfaction. But the interference from family to work is not reducing the job satisfaction. There are studies related to work-family conflict and family-work conflict with job satisfaction with mediating role (Huang, Hammer, Neal \& Perrin, 2004) and job satisfaction is not mediating it. In the study of Frone et al., (1992a) explained about work family interference that act as a mediating factor through which work domain factors negatively influence family satisfaction. There are other studies also related to family domain variables like stress, hours involvement etc as independent variable and family-work interference to job satisfaction. It is found that there is mediating effect but in this study interference as mediator has no impact.

Table 5. Findings of mediator effect between job satisfaction and family satisfaction

\begin{tabular}{|l|l|l|l|}
\hline Dependent & Independent & Mediator & Result \\
\hline Job Satisfaction & Family Satisfaction & Work-Family Interference & Not Significant \\
\hline Family Satisfaction & Job Satisfaction & Family-Work Interference & Not Significant \\
\hline
\end{tabular}


Family satisfaction has an impact on job satisfaction. But interference of family related aspects are not affecting the satisfaction of the job. In the same way job related interference are not affecting satisfaction of family. This understanding helps the company to put forth policies based on this. Flexible policies based on individual requirement help to provide satisfaction at family domain. This will have an impact on job satisfaction resulting in better performance.

\section{Managerial Implication}

A good environment for working has to be created for a better performance. So in order to manage human being and increase the productivity, understanding both job and family satisfaction is important. It is important for company to see that employees lead a happy family life. When policies are formulated these aspects have to be taken care. An employee whose family life is highly satisfied may contribute more to the company than a person who is less satisfied. Satisfaction with family life should not be taken delicately. This study clearly reveals the importance of family life for a better job life. An employee whose family life is highly satisfied may contribute more to the company than a person who is less satisfied. Satisfaction with family life should not be taken delicately. This study clearly reveals the importance of family life for a better job life. When policies are formulated these aspects have to be taken care. When family demands are met without any hassles, results in satisfaction. Companies have to create a favorable working environment to engross in the job and be committed to it. A focused mind towards job can contribute much to job compared to the one with issues related to job. An active effort has to be considered by the human resource department to create satisfaction among all its employees. This study is relevant to understand the relationship between the variables considered.

\section{Reference}

Beutell and Greenhaus (1985). Sources of conflict between work and family roles, Academy of Management Review.
10(1):76-88. https://doi.org/10.2307/258214, https://doi. org/10.5465/amr.1985.4277352

Carlson, D.S. and Kacmar, K.M. (2000). Work -family conflict in the organization: Do life role values make a difference, Journal of Management. 26:1031-54. https://doi.org/10.1177/014920630002600502, https:// doi.org/10.1016/S0149-2063(00)00067-2.

Carlson, D.S., Kacmar, K.M. and Williams, L.J. (2000). Construction and initial validation of a multidimensional measure of work-family conflict, Journal of Vocational Behavior. 56:249-76. https://doi.org/10.1006/jvbe.1999.1713

Duxbury, Higgins and Mills. (1990). After-hours telecommuting and work-family conflict: A Comparative analysis, Information Systems Research. 3(2):173-90.

Ford, M.T., Heinen, F.B. and Langkamer, K.L. (2007). Work and family satisfaction and conflict: A meta-analysis of cross - domain relations, Journal of Applied Psychology. 92(1):57-80. https://doi.org/10.1037/0021-9010.92.1.57. PMid: 17227151.

Frone, M. R., Russell, M. and Cooper, M. L. (1992a). Antecedents and outcomes of work-family conflict: Testing a model of the work-family interface, Journal of Applied Psychology. 77:65-78. https://doi. org/10.1037/0021-9010.77.1.65. PMid: 1556042.

Frone, M.R., Yardley, J.K. and Markel, K.S. (1997). Developing and testing an integrative model of the workfamily interface, Journal of Vocational Behavior. 50:14567. https://doi.org/10.1006/jvbe.1996.1577.

Huang, Hammer, Neal and Perrin (2004).The relationship between work-to-family conflict and family-to-work conflict: A longitudinal study, Journal of Family and Economic Issues. 25(1):79-100. https://doi.org/10.1023/ B:JEEI.0000016724.76936.a1.

Luk, D.M. and Shaffer, M.A. (2005). Work and family domain stressors and support: Within- and crossdomain influences on work-family conflict, Journal of Occupational and Organizational Psychology. 78:489508. https://doi.org/10.1348/096317905X26741.

O’Driscoll, M.P., Brough, P. and Kalliath, T.J. (2004). Work/family conflict, psychological well-being, satisfaction and social support: A longitudinal study in New Zealand. Equality, Diversity, and Inclusion. An International Journal. 23(1):36-56. https://doi. org/10.1108/02610150410787846. 